\author{
Brehan Mohammed*, Dereje Tewabe, \\ Wonde Zelalem and Adane Melaku \\ Amhara Region Agricultural Research Institute, \\ Bahir-Dar Fisheries and Other Aquatic Life Research \\ Center, Ethiopia \\ Dates: Received: 18 February, 2016; Accepted: 01 \\ April, 2016; Published: 04 April, 2016 \\ *Corresponding author: Brehan Mohammed, \\ Amhara Region Agricultural Research Institute, \\ Bahir-Dar Fisheries and Other Aquatic Life Research \\ Center P.O.Box 794, Bahir-Dar, Ethiopia, Tel: \\ +251918389898; E-mail: talemye@gmail.com \\ www.peertechz.com \\ ISSN: 2455-8400
}

Keywords: Physical; Biological and chemical parameters; Fish species type

\section{Research Article \\ Physical, Chemical, Biological properties and fish species type of Geray reservoir, -W/Gojjam Zone, Ethiopia}

\section{Introduction}

Physico-chemical parameters of water play a significant role in the biology and physiology of fish [1]. Water quality is determined by the physical and chemical limnology of a reservoir [2] and includes all physical, chemical and biological factors of water that influence the beneficial use of the water. Water quality is important in drinking water supply, irrigation, fish production, recreation and other purposes to which the water must have been impounded.

Water quality deterioration in reservoirs usually comes from excessive nutrient inputs, eutrophication, acidification, heavy metal contamination, organic pollution and obnoxious fishing practices. The use of the physico-chemical properties of water to assess water quality gives a good impression of the status, productivity and sustainability of such water body [3]. The changes in physical characteristics like temperature, transparency and chemical elements of water such as dissolved oxygen, chemical oxygen demand, nitrate and phosphate provide valuable information on the quality of the water, the source of the variations and their impacts on the functions and biodiversity of a reservoir. Reservoirs are usually found in areas of water scarcity or excess, or where there are agricultural or technological reasons to have controlled water resources [4].

Treservoir has been studied. The results are expected to be a base line information for monitoring and tracking changes in the water quality as a result of the impact of human activities on the reservoir. Therefore the main aim of this study were to determine the physical, chemical and biological parameters of Geray reservoir and to identify the fish species in the reservoir.

\section{Materials and Methods}

\section{Study area}

Geray is located in Amhara Regional state Ethiopia, West Gojjam Administrative Zone, Jabitehnan and Finoteselam district, bordering, Shembekuma-Yedafas and Arebayitu-Insesa Kebeles. Three sites one from the inlet site, one from the open water and the other from the outlet was selected. In situ measurements in the morning at 4 o'clock samples of temperature, $\mathrm{pH}$, dissolved oxygen, salinity, Total Dissolved Solid, conductivity were done using YSI 556 multiprobe meter. Secchi measurement was done using secchi disk.

Palin test photometer 5000 was used for analysis of total hardness, alkalinity, nitrate, phosphate and ammonia test. Fish samples collected using 6, 8, 10 and $12 \mathrm{~cm}$ stretched size mesh gillnet by setting the net overnight. Descriptive statistics has been used to calculate the mean and standard deviation values of the parameters. Data has been analyzed using simple Excel sheet 2010 and SPSS V.20 (Figures 1-3).

\section{Results and Discussion}

\section{Alkalinity}

In the present study, the most of the physico-chemical parameters remained within favorable ranges for fish growth and survival (Table 
1). The mean value of the total alkalinity $83.6,82,80 \mathrm{mg} / \mathrm{L}$ in the open water, inlet and outlet side of the reservoir, respectively and were favorably well with the range given for lakes and reservoir by USEPA [5], and is an indicator to the good quality of the reservoir water. It is reported that total alkalinity above $40 \mathrm{mg} / \mathrm{L}$ is indicative of high productivity [6]. Thus the reservoir in good state that it may support good fish production.

\section{Total hardness}

In Geray reservoir during this study period 51.3, 50, $47.3 \mathrm{mg} / \mathrm{L}$ was the recorded mean total hardness value in the open water, inlet and outlet side, respectively which shows the water is soft. Water is soft when the mean range of the total hardness fell within (32-60 $\mathrm{mg} / \mathrm{L}$ ) [7]. From this we can conclude that the reservoir's water can be said soft.

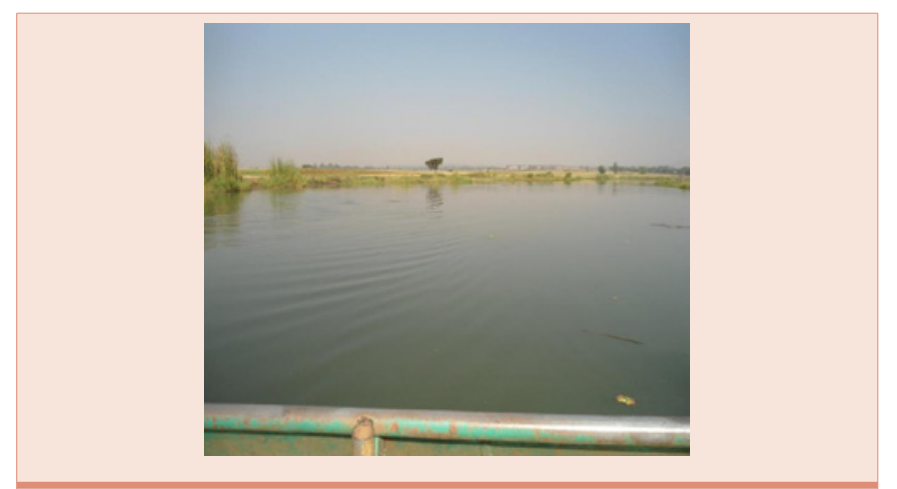

Figure 1: Open water site of Geray reservoir.

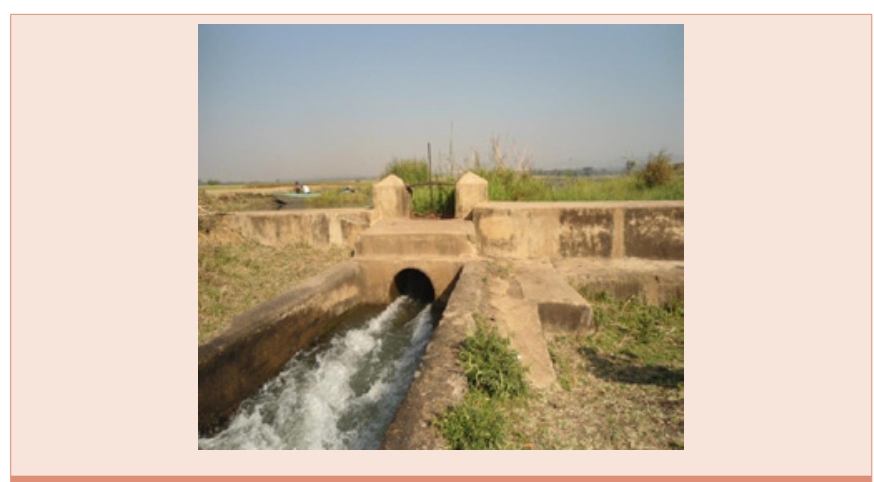

Figure 2: The Outlet site of the reservoir.

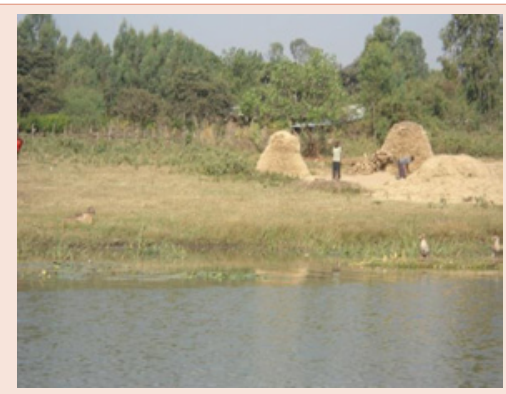

Figure 3: Inlet site of the reservoir.

\section{Phosphate}

The highest mean concentration of phosphate recorded was 0.71 $\mathrm{mg} / \mathrm{l}$ which was obtained from the inlet side. This higher concentration of phosphate might be due to inflow of domestic waste, agricultural runoff from the nearby farms because the inlet site is very near to the house of the inhabitants. Effects of human activities on the reservoir and its watershed are much reflected on the variations seen in nitrate, phosphate and possibly sulphate concentrations. The relatively high concentration of phosphate $(0.77 \mathrm{mg} / \mathrm{L})$ recorded and that of sulphate $(16.3 \mathrm{mg} / \mathrm{L})$ in the inlet side could have come from leaching and run-off of nitro-phosphate and sulphate fertilizers from nearby farm lands. Washing of cow dungs and bathing and washing with phosphate based detergents and soaps into the reservoir might have also caused the high concentration of the ions. These events might not stay in the current state but if the mismanagement of the reservoir continues it might led to cultural eutrophication of the reservoir with subsequent bloom in algae and changes to the water quality in the future. Desirable concentration of dissolved oxygen for most fish is $5 \mathrm{mg} / \mathrm{L}$ and above [8]. The mean DO of Geray reservoir was 7, 7, $7.26 \mathrm{mg} / \mathrm{L}$ in the open water, inlet and outlet site, respectively which shows the dissolved oxygen level was favorable or in desirable limit to sustain aquatic life in the reservoir.

\section{Secchi disk measurement}

The lowest mean value of Secchi disc transparency was recorded in the inlet side $31.4 \mathrm{~cm}$ showing little turbidity and low transparency. The transparency of water is affected in various seasons due to algal blooms and suspended sediments [9]. The mean secchi disc visibility, $34.06 \mathrm{~cm}$ and $55.1 \mathrm{~cm}$ in the open water and outlet side, respectively might probably reflect the depth of light penetration and this is good for a reservoir as plankton and fish will thrive in this pelagic region, thus making food available to fish.

\section{$\mathrm{pH}$}

Using the $\mathrm{pH}$ as a water quality index, Geray reservoir has good water quality with the mean $\mathrm{pH}$ of 7.29 in the open water, 6.96 in the inlet and 7.3 in the outlet site, since most natural waters have $\mathrm{pH}$ between 6.5 and 8.5 [10].

\section{Electrical conductivity}

lectrical conductivity as water quality index [11], Geray reservoir has? Good water quality. The results obtained were in169.3, 168, $170 \mu \mathrm{s} / \mathrm{cm}$ in the open, inlet and outlet sites, respectively. This will support diverse species of organisms. Dumont [12], also observed that species number decreases in water with high conductivity. The ranges of electrical conductivity and TDS values in the reservoir will support productive fisheries coupled with reservoirs shallowness. The two parameters could be used as morpho-edaphic index to estimate potential fish yields in reservoirs [13] (Table 2).

\section{Zooplankton density and composition in geray reservoir}

Three different taxa of zooplankton were collected (Table 3). Of these, the most abundant taxon was copepoda (666 ind. $/ \mathrm{m}^{3}$ of water with their juvenile stages "Nauplia?" or contributed $85 \%$ of total 
Table 1: Results of water quality parameters of the three sampling sites of Geray reservoir.

\begin{tabular}{|c|c|c|c|c|c|c|c|}
\hline Parameters & Sites & Mean & Std. Deviation & Parameters & Sites & Mean & Std. Deviation \\
\hline \multirow{3}{*}{ Phosphate $\mathrm{mg} \mathrm{L}^{-1}$} & Open water & 0.55 & 0.57 & \multirow{3}{*}{ Total hardness $\mathrm{mg} \mathrm{L}^{-1}$} & Open water & 51.3 & 7.50 \\
\hline & Inlet & 0.71 & .75719 & & Inlet & 50.0 & 11.13 \\
\hline & Out let & 0.44 & .43405 & & Out let & 47.3 & 17.50 \\
\hline \multirow{3}{*}{ Ammonia $\mathrm{mg} \mathrm{L}^{-1}$} & Open water & 0.08 & .04933 & \multirow{3}{*}{ Sulphate $\mathrm{mg} \mathrm{L}^{-1}$} & Open water & 3.66 & 1.154 \\
\hline & Inlet & 0.06 & .06245 & & Inlet & 16.3 & 14.04 \\
\hline & Out let & .0533 & .06807 & & Out let & 5.3 & 2.516 \\
\hline \multirow{3}{*}{ Nitrate $\mathrm{mg} \mathrm{L}^{-1}$} & Open water & 4.9613 & 1.89069 & \multirow{3}{*}{ Alkalinity $\mathrm{mg} \mathrm{L}^{-1}$} & Open water & 83.6 & 7.094 \\
\hline & Inlet & 3.1913 & 3.34808 & & Inlet & 82 & 7.21110 \\
\hline & Out let & 4.5033 & .73050 & & Out let & 80 & 13.22876 \\
\hline \multirow{3}{*}{ Nitrite $\mathrm{mg} \mathrm{L}^{-1}$} & Open water & .0616 & .03287 & \multirow{3}{*}{$\mathrm{DO}\left(\mathrm{mgL}^{-1}\right)$} & Open water & 7.01 & .75717 \\
\hline & Inlet & .0429 & .05484 & & Inlet & 7.00 & .70002 \\
\hline & Out let & .0626 & .03948 & & Out let & 7.26 & .47983 \\
\hline
\end{tabular}

Table 2: Results of water quality parameters of the three sampling sites of Geray reservoir.

\begin{tabular}{|c|c|c|c|c|c|c|c|}
\hline Parameters & Sites & Mean & Std. Deviation & Parameters & Sites & Mean & Std. Deviation \\
\hline \multirow{3}{*}{ pH } & Open water & 7.29 & .74969 & \multirow{3}{*}{ Salinity } & Open water & .08 & .00 \\
\hline & Inlet & 6.96 & .52048 & & Inlet & .08 & .00 \\
\hline & Out let & 7.30 & .77485 & & Out let & .08 & .00 \\
\hline \multirow{3}{*}{ Turbidity(NTU) } & Open water & 9.000 & 12.12436 & \multirow{3}{*}{ Conductivity $\left(\mu \mathrm{Scm}^{-1}\right)$} & Open water & 169.3 & 4.04 \\
\hline & Inlet & 15.000 & 4.58258 & & Inlet & 168 & 4.35 \\
\hline & Out let & 8.0000 & 5.19615 & & Out let & 170 & 6.50 \\
\hline \multirow[t]{2}{*}{$\mathrm{T}\left({ }^{\circ} \mathrm{C}\right)$} & Inlet & 22.88 & .69217 & \multirow[t]{2}{*}{ Secchi depth in cm } & Inlet & 31.4 & 27.66 \\
\hline & Out let & 22.70 & 1.7349 & & Out let & 55.1 & 37.51 \\
\hline \multirow{3}{*}{ TDS in $\mathrm{mgL}^{-1}$} & Open water & 110.7 & .00252 & & & & \\
\hline & Inlet & 109.3 & .00289 & & & & \\
\hline & Out let & 110 & .00400 & & & & \\
\hline
\end{tabular}

Table 3: Density and percentage relative abundance (\%RA) of zooplankton taxa of Geray reservoir.

\begin{tabular}{|l|l|l|}
\hline Type of zooplankton taxa & Ind./m & \% RA \\
\hline Bosmina & 95 & 11 \\
\hline Cyclopoid & 190 & 22 \\
\hline Daphnia & 95 & 11 \\
\hline Nauplia & 476 & 56 \\
\hline
\end{tabular}

Table 4: Density of zooplankton taxa (ind. $/ \mathrm{m}^{3}$ ) of Geray reservoir at the three sampling sites.

\begin{tabular}{|l|l|l|l|}
\hline Type of zooplankton taxa & Open water & Outlet & Inlet \\
\hline cyclopoid + nuplil??? & 1333 & 667 & 190 \\
\hline Daphnia & 0 & 95 & 190 \\
\hline Basmina??? & 0 & 95.2381 & 0 \\
\hline
\end{tabular}

zooplankton taxa), which was followed by Cladocera (190 inds. $/ \mathrm{m}^{3}$ or $15 \%)$. The density contributed and density in terms of individual per cubic meter of reservoir water and relative abundance of zooplankton are summarized below (Table 4).

The developmental stages of cyclopoid "Nauplia" were higher in their density in all study sites. Among the three study sites open water showed higher density of zooplankton, especially cyclopoid followed by outlet site. The inlet site was relatively low in zooplankton density.

\section{Fish species}

Fishing is their income generating activity next to crop production in the area. Fishers' daily catch is attractive. The species found in the reservoir were Cyprinus carpio, Varicorhinus Beso, Carasius Auratus and Oreochromis niloticus (Figures 4,5).

Gold fish species has been introduced by collaboration of ministry of agriculture and the national fisheries research center during the Derg regime (personal communication from the beuro of agriculture). It is a docile fish species, so easy to handle and fish in the reservoir and hence it is called Emuhay by the inhabitants.

Redbreast Tilapia - Tilapia rendalli is a fighting fish that delight in catching. It was introduced 25 years back during the Derge Regime, for the purpose of reducing vegetation cover of the Geray reservoir (pers. comm) (Figure 6).

\section{Conclusion}

As discussed in the result and discussion, most of the results of physico-chemical parameters monitored in the study fell within the range conducive for the survival of aquatic organisms and within the permissible level stated by most countries specially set by United State Environmental Protection Agency and World Health Organization (year). Thus, the water can be classified a good, stable and healthy for aquatic ecosystem. Most of the parameters result showed the water to be of good quality and will support and promote the survival of fish in the reservoir. 


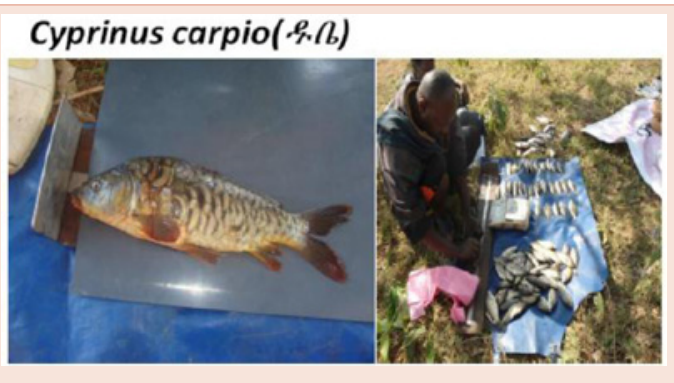

Figure 4: Cyprinus carpio found at Geray Reservoir.

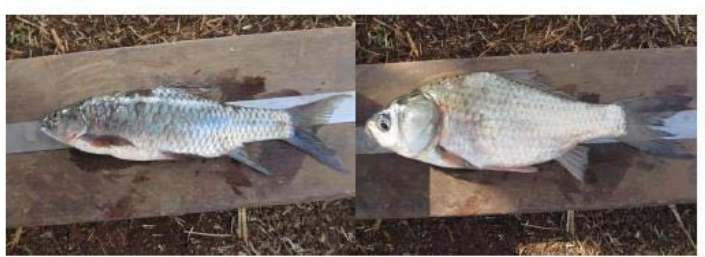

Varicorhinus beso $\mathrm{RH}$

Carasius auratus gold fish

Figure 5: Varcorhinus beso and carasius carasius found in Geray reservoir.

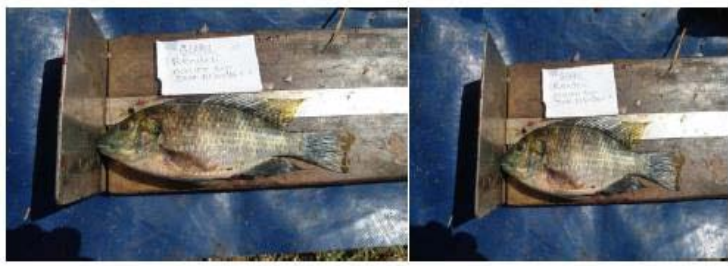

Figure 6: Tilapia randelli in Geray reservoir.

Based on the parameters investigated the only visible threat that might occur in this reservoir for the future to the water quality and fish production is cultural eutrophication which was more pronounced at the inlet site as a result of human activities on the site.

There is a tightly coupled interaction between physico-chemical and biological properties of water, hydrology, construction, operations and functioning reservoirs. Therefore, there should be continuous monitoring of reservoir impacts on fish biodiversity and fish production as reservoir ecosystem changes with time. It is important to know about water quality parameters and their management which have influence on growth and survival of aquatic organisms. Therefore, depending on this study result Geray reservoir is in a good condition of its water quality.

Despite the reservoir used the community for different aspects such as forage source for animals, for recreation and cultural festivity and supports the poor through generating income by selling the macrophytes, as a source of fingerlings of the different fish species to develop aquaculture and mainly for irrigation its sustainability is in question. The downstream community has decided to drain the reservoir to make extra canals for additional irrigation areas to find the simplest slope which might help for their crop but this might also be one threat for its sustainability in the future.

\section{Recommendation}

Although the current state of the reservoir is good the present mismanagement may harm its future sustainability of the reservoir, therefore, it is recommended that the local community and authorities from different organizations should join hands to protect this reservoir from being overexploited. Ministry of forestry and environment of Ethiopia should put up policies that should stop the various human activities which have been identified as a major threat to the sustainability of aquatic life for all reservoirs in the country.

The community should be awaked by workshops and training to make them aware while they are starting to exploit their resource. There should be a boundary between the community land and the reservoir.

\section{References}

1. Dhawan A, Kaur S (2002) Pig dung as pond manure: Effect on water quality, pond productivity and growth of carps in polyculture system. Naga, the ICLARM Quarterly 25: 11-14.

2. Thomaz SM, Lansac Tôha FA, Roberto MC, Esteves FA, Lima AF (1992) Seasonal variation of some limnological factors of Lagoa does. 25: 269-276.

3. Djukic N, Maletin S, Pujin V, Ivanc A, Milajonovic B (1994) Ecological assessment of water quality of Tisze by physico-chemical and biological parameters. Tisca Szeged 28: 37-40.

4. Wetzel RG (2000) Freshwater ecology: changes, requirements, and future demands. Liminology 1: 3-9

5. USEPA (1998) Water Quality Conditions in the United States: A Profile from the 1996, National Water Quality Inventory Report to Congress. Office of Water, Washington, DC.

6. Sugunan VV (1995) Reservoir fisheries of India. FAO Fish Tech. Pap. No. 345 Rome, 423.

7. Hanna (2003) The Hanna Catalog. Hanna Instruments Inc. Woonsocket RI, USA.

8. Bwala RL, Omoregie E (2009) Organic enrichment of fish ponds: Application of pig dung vs. tilapia yield. Pakistan Journal of Nutrition 8: 1373-1379.

9. Horn AJ, Goldman CR (1994) Limnology $2^{\text {nd }}$ McGraw-Hill, Inc 1-576.

10. Tepe Y, Mutlu E (2005) Physico-chemical characteristics of Hatay Harbiye Spring water, Turkey. J of the Inst of Sci Tech of Dumlupinar University 6: 77-88.

11. Moore WL (1989) NALMS? Management guide for lakes and reservoirs. North American lake management society. Madison, WI USA 44.

12. Dumont HJ (1999) The species richness of reservoir plankton and the effect of reservoirs on plankton dispersal (with particular emphasis on rotifers and cladocerans). In: Tundisi JG, Straskraba M (Eds.). Theoretical reservoir ecology and its applications. IIE, Backhuys Publishers, Brazilian Academy of Science: 477-491.

13. Jenkins RM (1982) The morpho edaphic index and reservoir fish production. Transactions of the American Fisheries Society 111: 133-140.

Copyright: (C) 2016 Mohammed B, et al. This is an open-access article distributed under the terms of the Creative Commons Attribution License, which permits unrestricted use, distribution, and reproduction in any medium, provided the original author and source are credited. 